\title{
Relationships between grain yield and agronomic traits of rice in southern China
}

\author{
Hua Zhao ${ }^{1,2}$, Zhaowen Mo ${ }^{1}$, Qingshan Lin ${ }^{2}$, Shenggang Pan ${ }^{1}$, Meiyang Duan ${ }^{1}$ Hua Tian ${ }^{1}$, Shuli Wang ${ }^{1}$, \\ and Xiangru Tang ${ }^{1 *}$
}

\begin{abstract}
${ }^{1}$ South China Agricultural University, College of Agriculture /Scientific Observing and Experimental Station of Crop Cultivation in South China, Ministry of Agriculture P.R. China, Guangzhou 510642, China.

"Corresponding author (tangxr@scau.edu.cn).

${ }^{2}$ Guangdong Province General Station for Agriculture Technology Extension, Guangzhou 510520, China.
\end{abstract}

Received: 28 July 2019; Accepted: 28 October 2019; doi:10.4067/S0718-58392020000100072

\begin{abstract}
Field experiments were conducted to evaluate the grain yield and agronomic traits of inbred and hybrid rice (Oryza sativa L.) 'Yuxiangyouzhan' and 'Shenliangyou 58 xiangyouzhan' at 11 different planting sites during 2013-2017 in Southern China. The grain yield, growth period, panicle number $\mathrm{m}^{-2}$, productive tiller percentage, plant height, panicle length, grain number per panicle, filled grain number per panicle, filled grain percentage, and grain weight were evaluated. Results indicated that 'Shenliangyou 58 xiangyouzhan' produced higher grain yields than 'Yuxiangyouzhan' which was attributed to high grain weight and panicle length. Grain yield showed an increasing trend during 2013-2017 and the yield gaps among different years were attributed to differences in plant height, filled grain percentage and grain weight. The differences in grain yield among sites were mostly due to the combination effect of the agronomic traits which was greatly affected by the different climate conditions. The grain yield was significantly and positively correlated with the plant height, grain number $\mathrm{m}^{-2}$, filled grain number per panicle, filled grain percentage and grain weight. Moreover, principal components analysis (PCA) suggested that grain number per panicle and filled grain number per panicle are critical parameters attributed to grain productivity. Therefore, flowering and post-flowering stage is the most critical in this regard to improve the grain number and filled grain number per panicle to get better yields in the agro-climatic conditions of southern China.
\end{abstract}

Key words: Agronomic traits, China, grain yield, rice.

\section{INTRODUCTION}

Rice (Oryza sativa L.) is a staple food for more than half of the world population. Strategies are needed to increase the grain production to meet the food requirement of ever-increasing population (Zhang, 2007). It is impossible to increase rice planting area to gain higher rice production, so to increase grain yield per unit area and crop harvest frequency is the only option to get maximum returns (Ray and Foley, 2013; Peng, 2014). The development of hybrid rice resulted in rapid increment in rice yield (Yuan et al., 1994). Hybrid rice produced higher grain yield than inbred rice (Zhang and Wang, 2006). Peng et al. (1999) indicated that hybrid rice produced $9 \%$ higher yields than the best inbred cultivars in tropical irrigated lowlands. Other field studies suggested that grain yield of super hybrid rice yield over $10 \%$ higher than that of inbred rice (Zhang et al., 2009; Huang et al., 2010). Southern China is a typical region with adequate light and temperature resources quite suitable for double rice production systems.

Previous field studies showed yield differences among the same rice types/cultivars under different environmental conditions. For example, Taoyuan, Yunnan Province, China, had higher grain yield than other rice planting sites (Katsura 
et al., 2008), hence prevailing climatic conditions have huge impact in the growth and overall productivity of rice (Borrell et al., 1998; Jiang et al., 2015; 2016). The different environmental conditions results in the difference in temperature and radiation which ultimately affected grain yield formation in rice (Katsura et al., 2008; Mo et al., 2015; Li et al., 2019; Liu et al., 2019a; 2019b).

Moreover, a number of studies demonstrated that agronomic traits such as panicle number, spikelet number per panicle, spikelet filling percentage, and grain weight are highly related to grain yield, for example, Zhang et al. (2009) presented evidence that high grain yield of hybrid rice was associated with the spikelet number per panicle. Huang et al. (2010) suggested that grain yield in hybrid rice was highly attributed to panicle numbers. Ao et al. (2008) and Zhang et al. (2009) suggested that long growth duration was partially responsible for high biomass production in hybrid rice which attributed high grain yield. Besides, yield stability was positively correlated with grain filling percentage (Huang et al., 2018). So, it is imperative to study how regionally variable environmental conditions affect yield of hybrid and inbred rice cultivars as well as the physiological basis of hybrid rice cultivars responsible for high grain productivity. The present study was therefore conducted at 11 different sites in southern China for a time period of $5 \mathrm{yr}$ to assess yield variability among inbred and hybrid rice cultivars as well as the relationships between agronomic traits and grain yield.

\section{MATERIALS AND METHODS}

\section{Experimental description}

Field experiments were conducted in 11 different locations from February to July from 2013 to 2017 in the typical rice (Oryza sativa L.) production areas of Guangdong province, China. The 11 locations represent different rice planting regions of Guangdong Province, China, and they were as follows: northern regions (Heyuan, Qingyuan, Yunfu), north eastern regions (Heyuan), north western regions (Qingyuan, Yunfu), eastern regions (Chaozhou), central regions (Guangzhou, Huizhou, Jiangmen, Zhaoqing), and western regions (Zhanjiang, Maoming, Yangjiang). The average temperature, annual precipitation and annual sunshine hours of the experimental regions are shown in Table 1. The experimental fields were typical rice production field and had remained under rice cultivation for many years.

Two popular rice cultivars, i.e., Yuxiangyouzhan and Shenliangyou 58 xiangyouzhan, were used in each site. Yuxiangyouzhan is an inbred rice cultivar (growth duration $127 \mathrm{~d}$, with 135 grains per panicle, 87\% setting rate, and 22.7 g 1000-grain weight) developed by the Guangdong Academy of Agricultural Science and released in 2005. The 'Shenliangyou 58 xiangyouzhan' is a hybrid rice with a growth duration of $129 \mathrm{~d}, 145$ grains per panicle, $77 \%$ setting

Table 1. Average temperature, annual precipitation and annual sunshine hours of the experimental regions.

\begin{tabular}{lcccccc}
\hline Year & $\begin{array}{c}\text { Northern } \\
\text { regions }\end{array}$ & $\begin{array}{c}\text { North eastern } \\
\text { regions }\end{array}$ & $\begin{array}{c}\text { North western } \\
\text { regions }\end{array}$ & $\begin{array}{c}\text { Eastern } \\
\text { regions }\end{array}$ & $\begin{array}{c}\text { Central } \\
\text { regions }\end{array}$ & $\begin{array}{c}\text { Western } \\
\text { regions }\end{array}$ \\
\hline Average temperature, ${ }^{\circ} \mathrm{C}$ & & & & & & \\
2013 & 20.0 & 21.2 & 22.7 & 22.6 & 21.5 & 23.0 \\
2014 & 20.4 & 21.7 & 22.8 & 22.8 & 21.7 & 23.3 \\
2015 & 20.8 & 22.0 & 23.4 & 23.5 & 22.3 & 24.3 \\
2016 & 20.7 & 21.7 & 22.5 & 23.3 & 22.0 & 23.6 \\
2017 & 20.8 & 22.0 & 22.6 & 23.5 & 22.1 & 23.7 \\
\hline Annual precipitation, mm & & & & & & \\
2013 & 1654.0 & 1930.2 & 1736.2 & 1887.2 & 2095.4 & 2084.2 \\
2014 & 1517.0 & 1164.9 & 1788.2 & 1416.5 & 2234.0 & 1468.9 \\
2015 & 2128.7 & 1696.3 & 1848.1 & 1446.6 & 2471.9 & 1328.9 \\
2016 & 2428.9 & 2410.3 & 2132.5 & 2174.7 & 2939.7 & 1820.0 \\
2017 & 1397.2 & 1396.3 & 1275.8 & 1419.0 & 2067.4 & 1760.7 \\
\hline Annual sunshine hours, h $\mathrm{h}$ & & & & & & \\
2013 & 1731.5 & 1827.8 & 1624.2 & 1865.8 & 1582.9 & 1811.2 \\
2014 & 1886.2 & 1997.5 & 1744.5 & 1957.8 & 1613.6 & 1991.5 \\
2015 & 1540.8 & 1740.4 & 1583.0 & 2010.7 & 1594.3 & 2008.1 \\
2016 & 1629.2 & 1553.6 & 1466.2 & 1701.0 & 1451.8 & 1963.9 \\
2017 & 1738.9 & 1831.4 & 1605.4 & 1994.6 & 1671.5 & 1891.9 \\
\hline
\end{tabular}


rate, and $22.7 \mathrm{~g}$ 1000-grain weight, was developed by the Guangdong Academy of Agricultural Science and Tsinghua Shenzhen Longgang Research Institute, National Center for Engineering and Technology of Hybrid Rice and released in 2008. These cultivars have been widely grown by rice farmers in Guangdong province for their high yield potential.

Pre-germinated seeds were sown at nursing bed. The seedlings were transplanted at a hill spacing of $20 \mathrm{~cm} \times 20$ $\mathrm{cm}$ with three seedlings per hill. Seedling age at transplanting was around $25-35 \mathrm{~d}$. Total $750 \mathrm{~kg} \mathrm{hm}^{-2}$ of the compound fertilizer (N:P:K 15:15:15) was applied in two splits i.e., $60 \%$ as basal dose and $40 \%$ applied at tillering. The water management was as follows: flooding, midseason drainage, re-flooding and moist intermittent irrigation during the crop growth period. All other crop management practices, pest and weed management were performed following guidelines given for the province.

\section{Grain yield and yield related traits}

At maturity, grain yield was measured from $13.34 \mathrm{~m}^{2}$ sampling area within each plot, threshed manually, and then sun dried (adjusted to moisture content $\sim 14 \%$ ). Panicle number $\mathrm{m}^{-2}$ was calculated from $1 \mathrm{~m}^{2}$ with three replicates. Twelve plants were harvested in each plot to measure panicle length, grain number per panicle, filled grain number per panicle, and filled grain percentage. Five samples of 1000 grains were taken randomly from filled grains and weighed to record 1000-grain weight. Plant height was recorded from 10 plants in each plot whereas the productive tiller percentage was calculated by dividing the panicle bearing tillers with the total number tillers.

\section{Statistical analysis}

Data were analyzed using ANOVA, whereas means of cultivars, sites and years were compared based on the least significant difference test (LSD) at the $5 \%$ probability level. The correlation between the investigated parameters was investigated (Statistix 8, Analytical Software, Tallahassee, Florida, USA). For multivariate analysis, data were imported into the MetaboAnalyst software (http://www.metaboanalyst.ca; Xia et al., 2009).

\section{RESULTS AND DISCUSSION}

'Shenliangyou 58 xiangyouzhan' produced significantly higher grain yield than 'Yuxiangyouzhan'. The highest grain yield was obtained for $2017\left(6.83 \mathrm{t} \mathrm{ha}^{-1}\right)$ whilst significant lowest grain yield was recorded for $2013\left(6.29 \mathrm{t} \mathrm{ha}^{-1}\right)$. Different planting sites showed difference in grain yield. The highest grain yield was observed for Yunfu $\left(7.22 \mathrm{tha}^{-1}\right)$ whilst the lowest grain yield was detected for Yangjiang $\left(5.40 \mathrm{tha}^{-1}\right)$. The highest grain was detected at Yunfu $\left(7.98 \mathrm{t} \mathrm{ha}{ }^{-1}\right)$ in 2017, whilst the lowest grain was detected at Yangjiang (3.39 $\left.\mathrm{t} \mathrm{ha}^{-1}\right)$ in 2014. Over all, 'Shenliangyou 58 xiangyouzhan' produced higher and more stable grain yield than 'Yuxiangyouzhan'. Grain yield showed an increasing trend during 20132017 and varied for different growing sites (Table 2). Jiang et al. (2016) stated that hybrid rice yielded approximately 8\% more grain than inbred cultivars, besides, the reports of Zhang et al. (2009) and Huang et al. (2010) stated that grain yield of super hybrid rice was higher than that of inbred rice by more than $10 \%$. Jiang et al. $(2015 ; 2016)$ reported that the differences in grain yield between hybrid rice and inbred cultivars also depend on the external environmental conditions except genetic factors. Moreover, yield variations in yield components are largely responsible for yield variability for the inbred and hybrid rice cultivars, however external environmental conditions and cultivation practices could also be responsible for yield variability for the given rice types. Furthermore, difference between the percentage increment in our study and previous studies is mainly due to the long duration of rice cultivation owing to improvements in cultivation practices. Grain yield showed increasing trends during 2013-2017 across two cultivars and 11 planting sites, however, the strong annual precipitation and short annual sunshine hours in 2016 may relate to the slight decrease in grain yield in 2016 (Tables 1 and 2).

'Shenliangyou 58 xiangyouzhan' had higher growth period, plant height, panicle length, grain number per panicle, filled grain number per panicle, filled grain percentage, and grain weight but lower panicle number $\mathrm{m}^{-2}$ and productive tiller percentage than 'Yuxiangyouzhan'. Significant difference was observed in panicle length and grain weight between the two cultivars (Figure 1). Significant difference was observed in plant height, filled grain percentage and grain weight among the experimental years. The highest plant height, filled grain percentage and grain weight were observed in 2017, 2015 and 2015, respectively. The growth period, panicle number $\mathrm{m}^{-2}$, productive tiller percentage, panicle length, grain 
Table 2. Grain yield of inbred and hybrid rice cultivars in 5 years in 11 planting sites.

\begin{tabular}{|c|c|}
\hline Treatment & $\begin{array}{c}\text { Grain yield } \\
\mathrm{tha}^{-1}\end{array}$ \\
\hline \multicolumn{2}{|l|}{ Cultivars } \\
\hline Yuxiangyouzhan & $6.40 \mathrm{~b}$ \\
\hline Shenliangyou 58 xiangyouzhan & $6.66 \mathrm{a}$ \\
\hline \multicolumn{2}{|l|}{ Years } \\
\hline 2013 & $6.29 \mathrm{e}$ \\
\hline 2014 & $6.35 \mathrm{~d}$ \\
\hline 2015 & $6.62 b$ \\
\hline 2016 & $6.56 \mathrm{c}$ \\
\hline 2017 & $6.83 \mathrm{a}$ \\
\hline \multicolumn{2}{|l|}{ Sites } \\
\hline Chaozhou-Shantou & $6.22 \mathrm{f}$ \\
\hline Guangzhou & $6.68 \mathrm{~d}$ \\
\hline Heyuan & $5.93 \mathrm{~g}$ \\
\hline Huizhou & $6.69 \mathrm{~d}$ \\
\hline Jiangmen & $6.73 \mathrm{~cd}$ \\
\hline Maoming & $6.66 \mathrm{~d}$ \\
\hline Qingyuan & $7.02 b$ \\
\hline Yangjiang & $5.40 \mathrm{~h}$ \\
\hline Yunfu & $7.22 \mathrm{a}$ \\
\hline Zhanjiang & $6.78 \mathrm{c}$ \\
\hline Zhaoqing & $6.49 \mathrm{e}$ \\
\hline \multicolumn{2}{|l|}{ ANOVA } \\
\hline Cultivar (C) & $* *$ \\
\hline Year (Y) & $* *$ \\
\hline Site (S) & $* *$ \\
\hline $\mathrm{C} \times \mathrm{Y}$ & $* *$ \\
\hline $\mathrm{C} \times \mathrm{S}$ & $* *$ \\
\hline $\mathrm{Y} \times \mathrm{S}$ & $* *$ \\
\hline $\mathrm{C} \times \mathrm{S} \times \mathrm{Y}$ & $* *$ \\
\hline
\end{tabular}

number per panicle, filled grain number per panicle for the experimental years were about 124-126 d, 249.05-259.13, $61.68 \%-66.55 \%, 22.57-23.46 \mathrm{~cm}, 138.66-158.94$, and 122.27-132.78, respectively, across two cultivars and all growing sites (Figure 2). The panicle number $\mathrm{m}^{-2}$ and grain weight were 232.08-271.21 and 21.24-23.77 mg, respectively; the highest panicle number $\mathrm{m}^{-2}$ and grain weight was detected at Maoming. The productive tiller percentage, grain number per panicle, filled grain number per panicle, and filled grain percentage was 58.77\%-71.65\%, 138.06-193.22, 83.11-177.84, and $65.71 \%-92.13 \%$, respectively. The highest productive tiller percentage, grain number per panicle, filled grain number per panicle, and filled grain percentage at Yunfu. The longest growth period was investigated for Chaozhou-Shantou (135.8 d), whilst the shortest growth period was detected for Maoming (117.2 d). The plant height and panicle length were 98.64-113.21 and 21.28-24.48 cm, respectively (Figure 3). Similarly, a number of studies have revealed the correlation between grain yield and spikelet number per panicle (Zhang et al., 2009), panicles numbers (Huang et al., 2010), growth duration (Ao et al., 2008; Zhang et al., 2009), and grain filling percentage (Huang et al., 2018). It is possible that growth duration is related to the grain yield as it affects the other agronomic traits as well. Moreover, Table 3 showed that significant and positive correlations between grain yield and plant height $\left(\mathrm{r}=0.3868^{* *}\right)$, grain number $\mathrm{m}^{-2}\left(\mathrm{r}=0.3349^{* *}\right)$, filled grain number per panicle $\left(r=0.5205^{* *}\right)$, filled grain percentage $\left(r=0.4958^{* *}\right)$ and grain weight $\left(r=0.1876^{*}\right)$ was detected. In addition, productive tiller percentage showed significant but negative correlation with grain weight. Further, significant and negative correlation between panicle number $\mathrm{m}^{-2}$ and growth period, panicle length, grain number per panicle, filled grain number per panicle was also detected.

The biomass accumulation is important for grain yield formation. The improvement in rice yield potential might come from increased the biomass production (Peng et al., 1999). Laza et al. (2003) observed a weak relationship between grain 
Figure 1. Agronomy traits of inbred and hybrid rice cultivars plants. The data point means data in different years and locations for each variety.
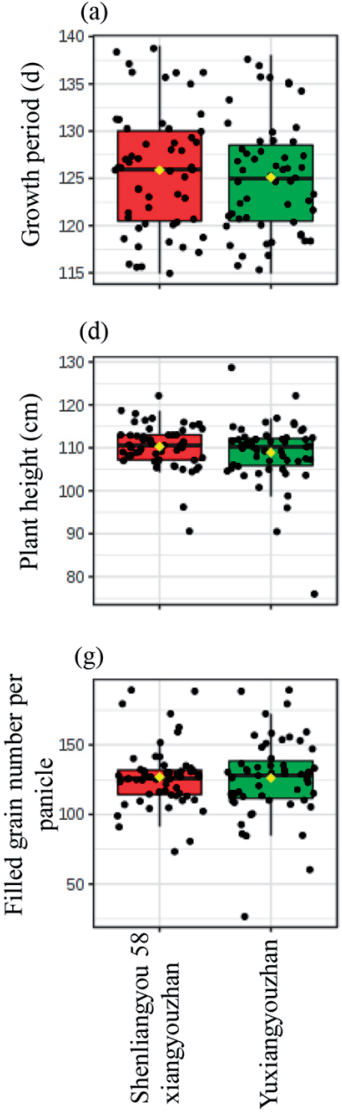

(b)

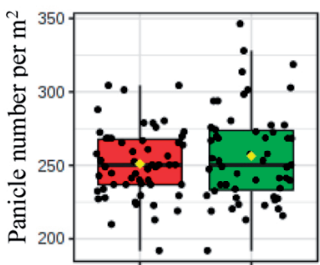

(e)

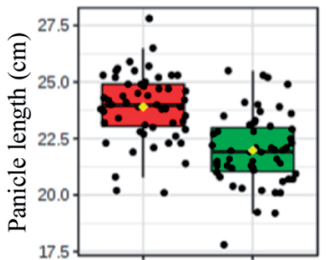

(h)

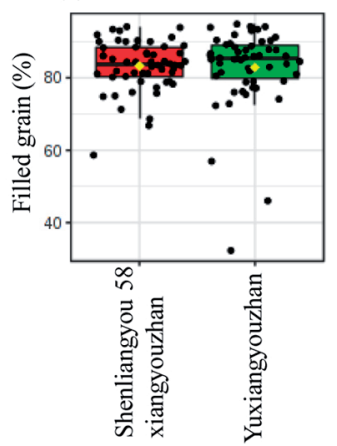

(c)

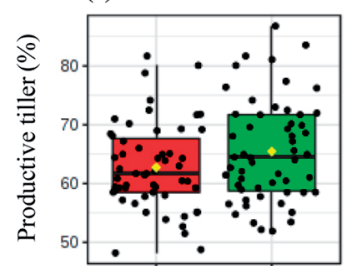

(f)

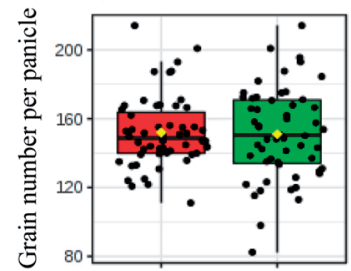

(i)

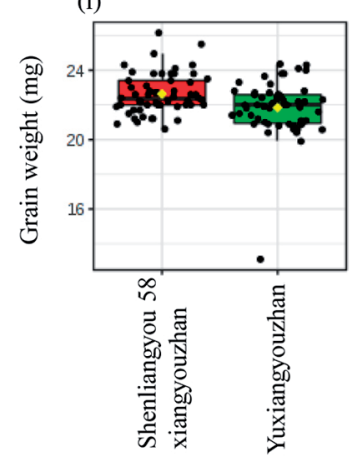

yield and biomass production. Jiang et al. (2015) suggested that higher grain yield in hybrid than in inbred cultivars in Changsha was attributed to higher grain weight and higher biomass production. In this study, the biomass of rice plant was not investigated and further study to evaluate the relationship between biomass and yield, yield related traits and other agronomy traits under long term study is needed.

The principal components analysis (PCA) of the investigated parameters revealed that F1, F2, F3, F4 and F5 accounted for $82.2 \%, 9.0 \%, 3.6 \%, 3.2 \%$ and $1.4 \%$, respectively (Figure 4). The grain number and filled grain numbers per panicle, and filled grain percentage were detected with high loading value for F1 whereas filled grain number per panicle and filled grain percentage were detected with high loading value for F2 (Table 4). These results suggested that grain yield was highly related to the grain number per panicle, filled grain number per panicle, and filled grain percentage.

Generally, suitable climatic conditions during the specific growth stage are critical for rice plant growth and grain yield. Therefore, further study to analyze the climate character during specific growth stages related to grain yield in long term experiments is needed. 
Figure 2. Agronomy traits of rice plants during 2013-2017. The data point means data of the two varieties in 11 locations for each year.

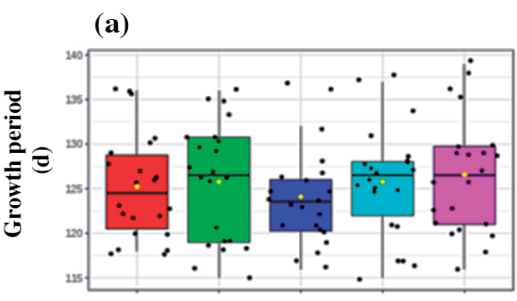

(d)
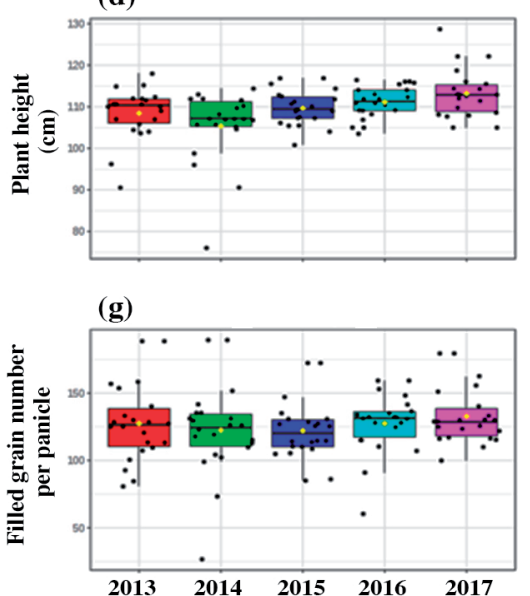

(b)

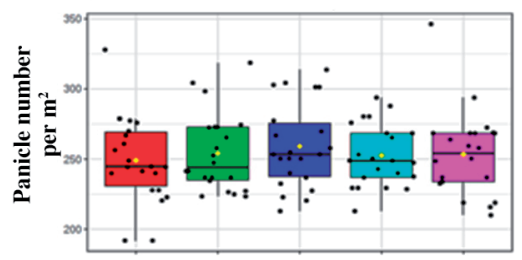

(e)
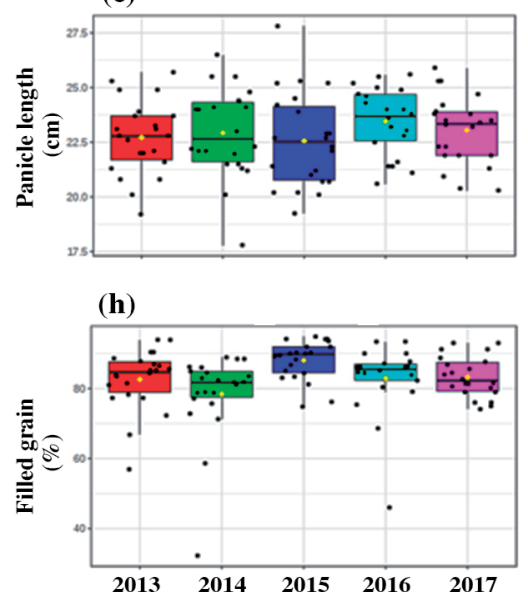

(c)
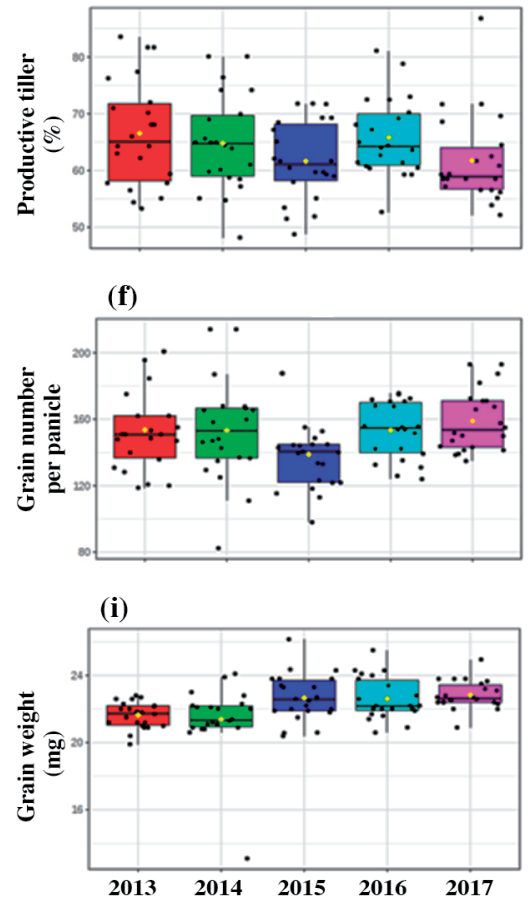

Figure 3. Agronomy traits of rice plants among different plant sites. The data point means data of the two varieties during 2013-2017.

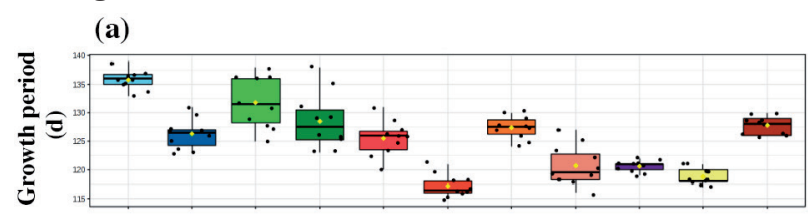

(c)

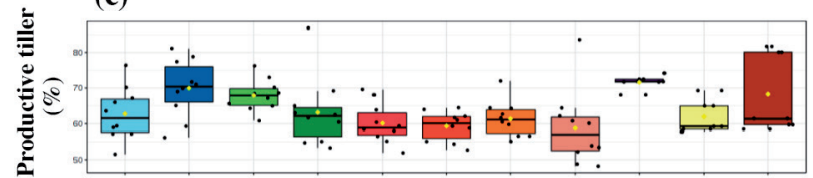

(e)
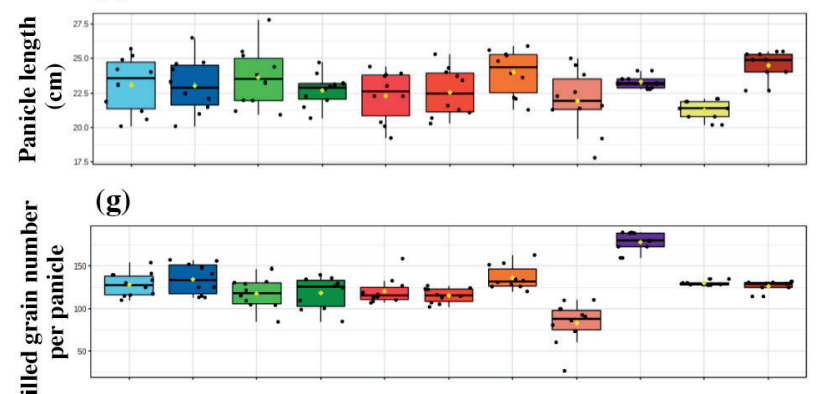

(i)

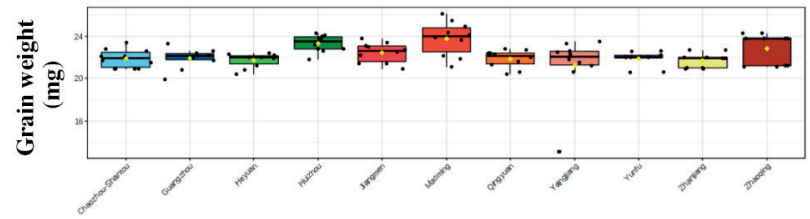

(b)

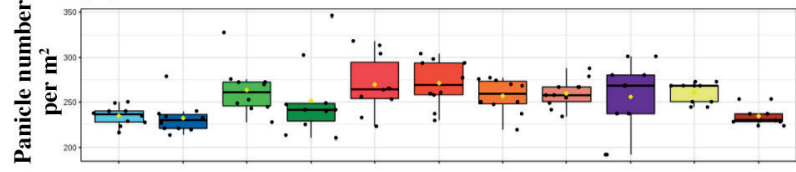

(d)

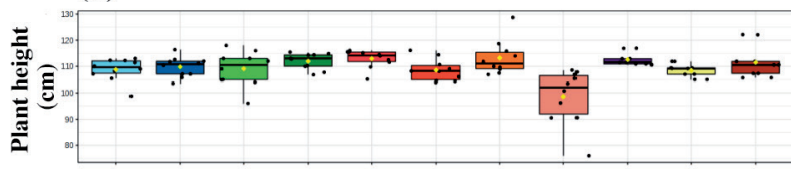

(f)

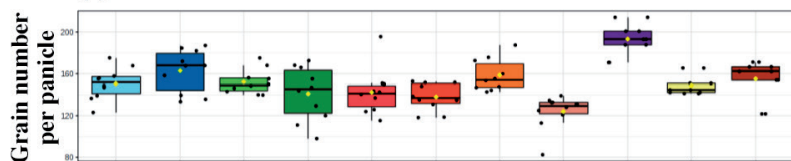

(h)

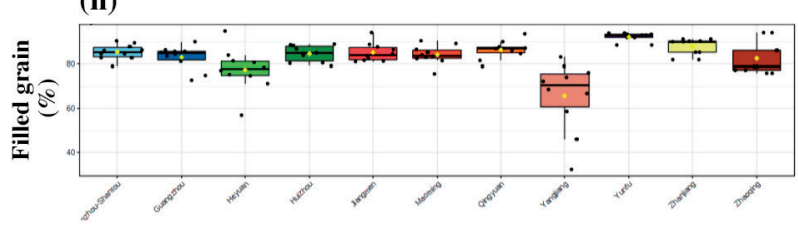


Table 3. Correlation analyses of the investigated parameters.

\begin{tabular}{llllllllll}
\hline Parameters & \multicolumn{1}{c}{ GY } & \multicolumn{1}{c}{ GP } & \multicolumn{1}{c}{ PN } & PT & PH & PL & GN & FGN & FGP \\
\hline GP & -0.0897 & & & & & & & & \\
PN & 0.0251 & -0.1998 & & & & & & & \\
PT & 0.0203 & 0.1119 & 0.0227 & & & & & & \\
PH & $0.3868^{* *}$ & $0.2609^{* *}$ & -0.0131 & -0.0057 & & & & & \\
PL & 0.1647 & $0.2839^{* *}$ & -0.2504 & 0.0525 & $0.3681^{* *}$ & & & & \\
GN & $0.3349^{* *}$ & 0.0489 & $-0.2711^{* *}$ & $0.4137^{* *}$ & $0.4064^{* *}$ & $0.4209^{* *}$ & & & \\
FGN & $0.5205^{* *}$ & -0.0217 & $-0.2459^{* *}$ & $0.3319^{* *}$ & $0.4751^{* *}$ & $0.3172^{* *}$ & $0.8945^{* *}$ & & \\
FGP & $0.4958^{* *}$ & -0.0594 & -0.0734 & 0.0296 & $0.4495^{* *}$ & 0.0595 & $0.2841^{* *}$ & $0.6676^{* *}$ & \\
GW & $0.1876^{*}$ & -0.0176 & -0.0565 & $-0.2179^{*}$ & $0.4607^{* *}$ & $0.3212^{* *}$ & 0.0053 & 0.1454 & $0.4273^{* *}$
\end{tabular}

GY: Grain yield; GP: growth period; PN: panicle number $\mathrm{m}^{-2}$; PT: productive tiller percentage; PH: plant height; PL: panicle length; GN: grain number per panicle; FGN: filled grain number per panicle; FGP: filled grain percentage; GW: grain weight.

$*, * *$ Significant at the $5 \%$ and $1 \%$ probability levels, respectively

Figure 4. Principal component analyses (PCA) of evaluated parameters.

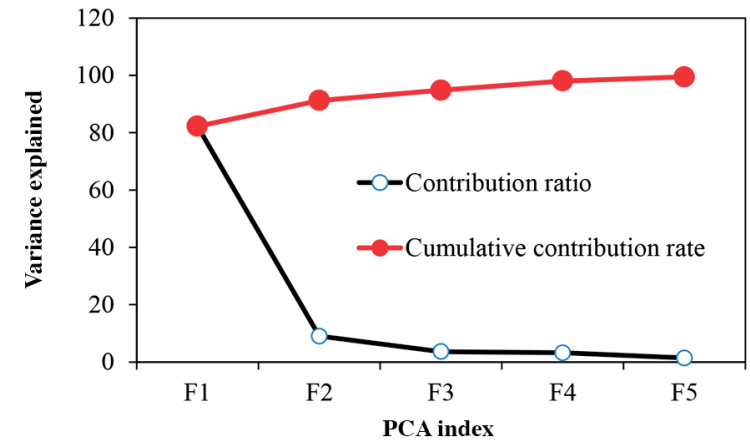

Table 4. Eigenvector of main factors analysis.

\begin{tabular}{lcrrrr}
\hline Factor & F1 & F2 & F3 & F4 & \multicolumn{1}{c}{ F5 } \\
\hline Grain yield & 0.0104 & 0.0249 & 0.0052 & 0.0005 & 0.0180 \\
Growth period & 0.0026 & -0.0812 & 0.0347 & -0.8030 & -0.5755 \\
Panicle number m $^{-2}$ & -0.0139 & 0.0110 & -0.0378 & 0.0163 & 0.1455 \\
Productive tiller percentage & 0.0901 & -0.2551 & -0.9102 & -0.1918 & 0.2364 \\
Plant height & 0.0881 & 0.1434 & 0.2794 & -0.5415 & 0.7463 \\
Panicle length & 0.0193 & -0.0275 & 0.0635 & -0.0789 & 0.0055 \\
Grain number per panicle & 0.6495 & -0.5630 & 0.2209 & 0.0217 & 0.0474 \\
Filled grain number per panicle & 0.7355 & 0.3821 & -0.0869 & 0.0922 & -0.1518 \\
Filled grain percentage & 0.1437 & 0.6635 & -0.1691 & -0.0898 & -0.0237 \\
Grain weight & 0.0043 & 0.0552 & 0.0431 & -0.0411 & 0.0928 \\
\end{tabular}

\section{CONCLUSIONS}

In conclusion, significant cultivar, year and site effect on grain yield was observed. The grain yield was significantly and positively correlated to plant height, grain number $\mathrm{m}^{-2}$, filled grain number per panicle, filled grain percentage and grain weight. Principal components analysis (PCA) suggested that grain number and filled grain number per panicle are critical parameters for grain yield determination. Overall, grain number and filled grain number per panicle are determinants of the grain yield for the inbred and hybrid rice cultivars grown in agro-climatic conditions of southern China. 


\section{ACKNOWLEDGEMENTS}

Financial support was provided by the Provincial Agricultural Development and Rural Work in 2017-The Improvement of Modern Seed Industry Project (Study on the Division of Rice in Guangdong, Yuenongji(2017) Nr 42). We thank Dr. Umair Ashraf for his contribution to this study.

\section{REFERENCES}

Ao, H.J., Wang, S.H., Zou, Y.B., Peng, S.B., Tang, Q.Y., Fang, Y.X., et al. 2008. Study on yield stability and dry matter characteristics of super hybrid rice. Scientia Agricultura Sinica 41:1927-1936 (in Chinese).

Borrell, A.K., Garside, A.L., Fukai, S., and Reid, D.J. 1998. Season and plant type affect the response of rice yield to nitrogen fertilization in a semi-arid tropical environment. Australian Journal of Agricultural Research 49(2):179-190.

Huang, L., Sun, F., Yuan, S., Peng, S., and Wang, F. 2018. Responses of candidate green super rice and super hybrid rice varieties to simplified and reduced input practice. Field Crops Research 218:78-87.

Huang, M.,Zou, Y.B., Jiang, P., Xia, B., Ibrahim, M., and Ao, H.J. 2010. Relationship between grain yield and yield components in super Hybrid rice. Agricultural Sciences in China 10:1537-1544.

Jiang, P., Xie, X.B., Huang, M.,Zhou, X.F., Zhang, R.C., Chen, J.N., et al. 2015. Comparisons of yield performance and nitrogen response between hybrid and inbred rice under difference ecological conditions in south China. Journal of Integrative Agriculture 14:1283-1294.

Jiang, P., Xie, X., Huang, M., Zhou, X., Zhang, R., Chen, J., et al. 2016. Potential yield increase of hybrid rice at five locations in southern china. Rice 9(1):11.

Katsura, K., Maeda, S., Lubis, I., Horie, T., Cao, W.X., and Shiraiwa, T. 2008. The high yield of irrigated rice in Yunnan, China 'A cross location analysis'. Field Crops Research 107:1-11.

Laza, M.R.C., Peng, S., Akita, S., and Saka, H. 2003. Contribution of biomass partitioning and translocation to grain yield under sub-optimum growing conditions in irrigated rice. Plant Production Science 6(1):28-35.

Li, S., Jiang, H., Wang, J., Wang, Y., Pan, S., Tian, H., et al. 2019. Responses of plant growth, physiological, gas exchange parameters of super and non-super rice to rhizosphere temperature at the tillering stage. Scientific Reports 9:10618.

Liu, K., Deng, J., Lu, J., Wang, X., Lu, B., Tian, X., et al. 2019a. High nitrogen levels alleviate yield loss of super hybrid rice caused by high temperatures during the flowering stage. Frontiers in Plant Science 10:357.

Liu, K., Yang, R., Lu, J., Wang, X., Lu, B., Tian, X., et al. 2019b. Radiation use efficiency and source-sink changes of super hybrid rice under shade stress during grain-filling stage. Agronomy Journal 111:1-11.

Mo, Z., Li, W., Pan, S., Fitzgerald, T.L., Xiao, F., Tang, Y., et al. 2015. Shading during the grain filling period increases 2-acetyl-1-pyrroline content in fragrant rice. Rice 8(1):9.

Peng, S.B. 2014. Reflection on China's rice production strategies during the transition period. Scientia Sinica Vitae 44:845-850. doi:10.1360/052014-98.

Peng, S.B., Cassman, K.G., Virmani, S.S., Sheehy, J.E., and Khush, G.S. 1999. Yield potential trends of tropical rice since release of IR8 and the challenge of increasing rice yield potential. Crop Science 39:1552-1559.

Ray, D.K., and Foley, J.A. 2013. Increasing global crop harvest frequency: recent trends and future directions. Environmental Research Letter 8:44041.44050.

Xia, J., Psychogios, N., Young, N., and Wishart, D.S. 2009. MetaboAnalyst: a web server for metabolomic data analysis and interpretation. Nucleic Acids Research 37(Web Server issue):W652-W660.

Yuan, L.P., Yang, Z.Y., and Yang, J.B. 1994. Hybrid rice in China. p. 143-147. In Virmani, S.S. (ed.) Hybrid rice technology: new developments and future prospects. International Rice Research Institute, Los Baños, Philippines.

Zhang, Q.F. 2007. Strategies for developing green super rice. Proceedings of the National Academy of Sciences of the United States of America 104:16402-16409.

Zhang, Y.B., Tang, Q.Y., Zou, Y.B., Li, D.Q., Qin, J.Q., Yang, S.H., et al. 2009. Yield potential and radiation use efficiency of "super" hybrid rice grown under subtropical conditions. Field Crops Research 114:91-98.

Zhang, Q., and Wang, G. 2006. Yield of inbred rice and hybrid rice and soil nutrient balance under long-term fertilization. Plant Nutrition and Fertilizer Science 12(3):340-345. 